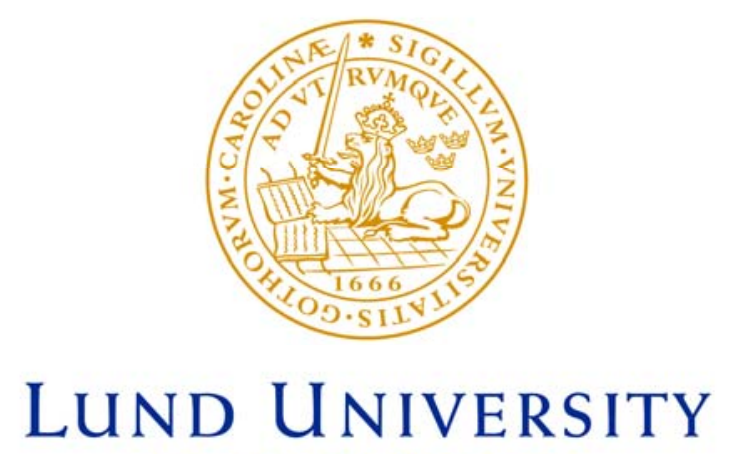

Faculty of Medicine

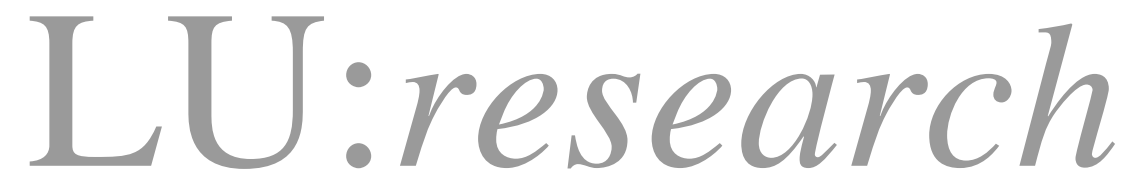

Institutional Repository of Lund University

This is an author produced version of a paper published in Artificial organs. This paper has been peer-reviewed but does not include the final publisher proof-corrections or journal pagination.

Citation for the published paper:

Kurkus, Jan and Nilsson, Rune and Lindén, Ola and Schonstrom, Niki and Sandberg, Bengt E B and Tennvall, Jan.

"Biocompatibility of a novel avidin-agarose adsorbent for extracorporeal removal of redundant radiopharmaceutical from the blood."

Artificial organs, 2007, Vol: 31, Issue: 3, pp. 208-14.

http://dx.doi.org/10.1111/j.1525-1594.2007.00366.x

Access to the published version may require journal subscription.

Published with permission from: Blackwell 


\title{
Biocompatibility of a novel avidin-agarose adsorbent for extracorporeal removal of redundant radiopharmaceutical from the blood
}

\author{
Jan Kurkus ${ }^{1}$, Rune Nilsson ${ }^{2}$, Ola Lindén ${ }^{3}$, Niki Schönström ${ }^{2}$, \\ Bengt E.B. Sandberg ${ }^{2}$, Jan Tennvall ${ }^{3}$
}

Departments of Nephrology ${ }^{1}$ and Oncology ${ }^{3}$, Lund University Hospital and Mitra Medical $\mathrm{AB}^{2}$, Lund, Sweden

Address correspondence and reprint requests to Jan Kurkus, Department of Nephrology, Lund University Hospital, SE-221 85 Lund, Sweden, E-mail: jan.kurkus@med.lu.se 


\section{Abstract}

The use of monoclonal antibodies (MAbs) in cytotoxic conjugates (radionuclides, toxins or drugs) for targeting tumor cells is restricted due to toxicity in vital organs. Through improved tumor targeting, it is possible to administer larger amounts of such labeled MAbs, thus improving the ability to eradicate tumor cells without increased normal organ toxicity. Extracorporeal affinity adsorption treatment (ECAT) has therefore been developed using an avidin-agarose (AA) adsorbent with high binding affinity for the biotinylated radiolabeled MAb, rituximab. During ECAT, excess radioimmunoconjugates, not bound to the tumor cells, can be removed improving tumour targeting. The present study was performed to estimate the biocompatibility of the AA adsorber. Seven patients with B-cell lymphoma not responding to conventional treatment were studied. During the ECAT procedure, blood (B) components, plasma (P) complement fragments C3a, C5a, and P-bradykinin were analysed, and other laboratory tests were carried out. Slight decreases in B-hemoglobin (8.3\%), B-thrombocytes (11.4\%), and P-albumin (14.3\%) were observed, and could be explained by the dilution of the blood with normal saline and acid citrate dextrose. The AA adsorbent had no effect on the blood cells, immunological status or P-bradykinin level. The AA adsorber demonstrated good hemocompatibility and biocompatibility, without any side effects in the patients.

\section{Key words}

Avidin-agarose, Biocompatibility, Tumor-specific antibodies, Radionuclide, Hemoadsorption. 


\section{Introduction}

New indications and technical progress have led to increasing interest in the application of extracorporeal affinity adsorption in a variety of settings. The treatment of tumors with monoclonal antibodies (MAbs) labeled with radionuclides, toxins, enzymes or cytostatic drugs are examples of areas in which affinity adsorption may be useful in clinical applications $(1,2)$. Whereas this kind of targeted therapy, in the form of radioimmunotherapy, has shown positive results for subgroups of hematopoietic neoplasms, solid tumors have been less responsive. Radioimmunotherapy is limited by the radiation-absorbed dose to radiosensitive vital organs, for example, bone marrow, lungs, liver and kidney. Removal of circulating radiolabeled MAbs after the tumor tissue has been optimally targeted should permit the administration of higher amounts of radioactivity to patients, resulting in a higher absorbed dose to the tumor. A novel extracorporeal affinity adsorption treatment (ECAT) device (MitraDep, Mitra Medical $\mathrm{AB}$, Lund, Sweden ), which removes biotinylated and radiolabeled MAbs from the circulation by passing whole blood over a filter coated with avidin, has been tested (3). The device contains a disposable, single-use avidin-agarose (AA) adsorbent. Avidin (protein isolated from hen egg white) is covalently linked to agarose and intended for the specific removal of biotinylated substances from the blood circulation by means of a biochemical affinity interaction between avidin and biotin (vitamin H). The efficiency of the ECAT procedure in the depletion of avidin-binding ${ }^{90} \mathrm{Y}$-radioactivity in the whole blood was very high, approaching 96\% (2).

Extracorporeal blood circulation involves specific interactions between blood components and artificial materials $(4,5)$, which may produce side effects of varying kinds and intensity (6). If no harmful interactions take place, the material is said to be biocompatible. A lack of biocompatibility may result in complement activation, cytokine production, activation of 
blood cells and initiation of coagulation process, as well as activation of the kallikreinkininogen pathways. Although the ECAT procedure is not intended to be repeated, as in the case of hemodialysis, high biocompatibility of the device is very important, as the treatment has to be completed within a certain time after the administration of excess amounts of radioimmunoconjugates. Any interruption in the procedure due to short-term clinical complications may lead to radiation-induced toxic side effects in vital organs.

Good biocompatibility upon contact with whole human blood in one passage through the AA adsorbent has been demonstrated in a previous study ex vivo (7). In the present study, the biocompatibility of AA adsorber during ECAT was tested in the first in vivo study in patients being treated for malignancies. This involved monitoring of blood components, the complement fragments C3a, C5a, and bradykinin, and other laboratory tests during ECAT. The clinical aspects of the study, which has been primarily intended to check the effectiveness of the adsorption procedure and to determine the biodistribution and safety of the radioimmunoconjugate, have been presented elsewhere (2).

\section{Material and methods}

Seven patients (five men, two women) with B-cell lymphoma not responding to conventional treatment (surgery, local radiation and/or chemotherapy) underwent the ECAT procedure according to the present study protocol approved by the Etics Committee of Lund University. All the patients gave their written consent to participate in the study. The mean age was 57 years (28-71 years), and average body weight was $70.1 \mathrm{~kg}(55-89 \mathrm{~kg})$. Details of inclusion and exclusion criteria are given elsewhere (2). During the ECAT procedure the whole blood was filtered extracorporeally, via a central vein catheter, through the AA adsorbent. The adsorbent was packed in a $200 \mathrm{~mL}$ column between two filters to avoid leakage of the adsorbent beads into the blood circulation. A bypass valve enables the passage of blood 
around the affinity adsorbent at start-up and at the end of the treatment (for details see [2]). Two standard dialysis Luer connectors join the device to the tubing set of the blood monitor (Fresenius 4008 Mitra hemoadsorption system, Fresenius Hemocare, Bad Homburg, Germany). The set up of the extracorporeal blood circuit is shown in Fig. 1. The column housing was sterilized with $\gamma$ radiation and filled, using an aseptic process, with AA adsorbent separately sterilized with $\gamma$ radiation. The chimeric mouse/human anti-CD $20 \mathrm{MAb}$, rituximab (Mabthera, Roche, Basel, Switzerland), conjugated to a radionuclide and biotin was used as a therapeutic anti-lymphoma agent. To facilitate the labeling of the naked antibody and to ensure that the ratio of biotin to radionuclide was $1: 1$, a series of trifunctional structures have been developed (MitraTag reagents \#1033, Mitra Medical AB, Lund, Sweden) (8). The trifunctional chelator, 3-(13'-thioureabenzyl DOTA)trioxadiamine-1-(13"'-biotin-Asp$\mathrm{OH}$ )trioxadiamine-5-isothiocyanato-aminoisophtalate, was used to label the antibody rituximab with ${ }^{111} \mathrm{In}$ or ${ }^{90} \mathrm{Y}$. The preparation of the trifunctional chelator has been described previously by Wilbur et al. (9). Details of the amount of antibodies and the amount of activity administered, the absorbed doses to organs, have been presented elsewhere (2).

\section{The ECAT procedure}

The blood volume of the patient was calculated according to Nadler's formula (10). During a period of 3 hours, the blood volume was processed three times at a blood flow rate adjusted to process $1 \mathrm{blood} v \mathrm{vol} / \mathrm{h}$ (Table 1 ). An anticoagulation agent was given in the form of a bolus dose of heparin to the patient before the start of the procedure, combined with continuous infusion of acid citrate dextrose solution, formula A (ACD-A, sodium citrate $\mathrm{H}_{2} \mathrm{O}, 74.8$ $\mathrm{mmol} / \mathrm{L}$; citric acid, $38.0 \mathrm{mmol} / \mathrm{L}$; dextrose $\mathrm{H}_{2} \mathrm{O} 124.7 \mathrm{mmol} / \mathrm{L}$ ) to the extracorporeal circuit during ECAT at a dose related to the blood flow; the ACD-A : blood mixing ratio was 1:20. The priming volume of the extracorporeal blood circuit was $300 \mathrm{~mL}$ (200 mL AA adsorber 
and $100 \mathrm{~mL}$ tubing set including drip chamber). The technical performance of the system was monitored every 15 min by measuring the patient's blood pressure, heart rate, body temperature, effective blood flow, infusion rate of ACD-A, the pressure at the inlet to and return line from the adsorber, and the volume of blood processed. Calcium chloride solution $(0.45 \mathrm{mmol} / \mathrm{mL})$ was administered intravenously during ECAT at a dose of between 5 and 10 $\mathrm{mL}$ to avoid hypocalcemia.

\section{Laboratory tests}

Blood samples for laboratory tests were taken from the patients before starting and immediately after completion of the treatment, and additionally 15 and 30 minutes after starting to determine leukocytes and 30 minutes after starting before and after the AA adsorber to determine thrombocytes. Blood samples for determination of complement fragments $\mathrm{C} 3 \mathrm{a}, \mathrm{C} 5 \mathrm{a}$, and bradykinin were taken at the start of ECAT, 15 and 30 minutes after the start, before and after the AA adsorber, and after completion of the treatment. Special precautionary measures were taken by the staff to avoid unnecessary exposure to radiation from the patients and blood samples.

Standard laboratory techniques were used for the determination of blood (B) hemoglobin, Bleukocytes (including differentiation), B-thrombocytes, B-reticulocytes, plasma (P) lactate dehydrogenase (LDH) and serum (S) ionized calcium. P-protein analysis to determine albumin, $\alpha-1$ antitripsin, C-reactive protein, orosomucoid, haptoglobin, $\operatorname{IgG}, \operatorname{IgM}$ and $\operatorname{Ig} A$ was performed with immunoturbidimetry, sum of these results was presented as total protein values. P-fibrinogen was analyzed with a photometric method. Plasma levels of complement fragments C3a and C5a were measured using commercial enzyme-linked immunoassays (Human C3a and C5a Opteia Kit, Becton Dickinson PharMingen, San Diego, CA, USA). The assays were performed according to the manufacturer's instructions. P-bradykinin was 
determined with a commercial enzyme-linked immunoassay (Markit-M Bradykinin Kit, Dainippon Pharmaceutical Co. Ltd, Osaka, Japan). The assays were performed according to the manufacturer's instructions with minor modifications of the procedure (11).

Blood samples were taken between 2 and 4 weeks prior to ECAT and 42 and 90 days after the ECAT procedure to investigate the possibility of avidin leakage from the adsorber into the patient's circulation, resulting in an immune reaction against avidin. The ELISA assay used has a detection limit of $10 \mathrm{ng}$ antibody $/ \mathrm{mL}$.

\section{Results}

The clinical observations during ECAT are presented in Table 2. Neither fatigue nor exhaustion was apparent, nor were any significant differences noted in heart rate, systolic or diastolic blood pressure, or body temperature. Adverse events were limited to catheter-related infection requiring antibiotic treatment in two patients. No fever, shivering, chills, or respiratory difficulties were observed. In one patient arrhythmia related to insertion of the central vein catheter occurred, but this was easily relieved and was not directly related to ECAT. During the procedure no bleeding episodes in the patients or coagulation problems in the extracorporeal circulation were observed. Blood circulation through the adsorber was uneventful without elevation of the inflow pressure (Table 2) reflecting an adequate anticoagulation regimen without excessive thrombus formation. The blood tests (Table 3) revealed that the B-hemoglobin level was slightly decreased from 121 to $111 \mathrm{~g} / \mathrm{L}$ during the study (8.3\%) but there were no signs of hemolysis (normal value of haptoglobin and LDH before and after treatment). B-leukocytes were unchanged 15 and 30 minutes after the start of ECAT but increased slightly at the end of ECAT (Fig. 2). This corresponded to an increase in neutrophils in the differential counts. B-thrombocytes decreased from 142 to $12310^{9} / \mathrm{L}$ (13.4\%) during ECAT (Fig. 3), as well as P-albumin from 35 to $30 \mathrm{~g} / \mathrm{L}$ (14.3\%) and this, as 
well as reduction in B-hemoglobin, can be explained by the dilution of the blood caused by normal saline and ACD-A administration during ECAT. The level of S-ionized calcium decreased slightly during ECAT (from 1.21 to $1.13 \mathrm{mmol} / \mathrm{L}$ i.e. $6.6 \%$ ) due to dilution and ACD-A administration. No signs of hypocalcemia were observed. Plasma values of orosomucoid, C-reactive protein, $\operatorname{IgG}, \operatorname{IgA}$, IgM, and fibrinogen were decreased by $10.8-$ $12.0 \%$ after ECAT, corresponding to the P-albumin decrease seen during ECAT, due to dilution.

Serum levels of complement fragments $\mathrm{C} 3 \mathrm{a}$ and $\mathrm{C} 5 \mathrm{a}$ were essentially unchanged during ECAT (Fig. 4) ruling out any significant activation, but a slight elevation of S-C3a and S-C5a above normal values was observed in three patients after the passage of blood through the AA adsorber for 30 minutes after the start of ECAT. Two of these patients showed elevated values of these complement fragments before and throughout the period of treatment. P-bradykinin remained within the normal range during ECAT (Fig. 5). No antiavidin antibodies could be detected in the patients' serum samples.

\section{Discussion}

The patients in this study had undergone intensive lymphoma treatment with many standard therapeutic procedures before they were given the course of radioimmunotherapy with ECAT. As a consequence, their immunological responses could have been suppressed, leading to a weaker reaction to the extracorporeal hemoadsorption process. This should be borne in mind when evaluating the results.

During this procedure the patients' vital signs were stable and no symptoms related to the extracorporeal volume changes or vasovagal hypotensive episodes could be observed. This can be explained by infusion of normal saline and ACD-A during the procedure. All the patients were in positive fluid balance at the end of ECAT and the blood dilution, which was 
estimated to be about $17 \%(16-19 \%)$, led to a decrease in blood values of B-hemoglobin (8.3\%), B-thrombocytes (13.4\%) and P-proteins (10.8-14.3\%). No hypersensitivity reactions to the materials used in the ECAT procedure, such as pruritus, urticaria, nausea, heat sensation, dyspnea, skin eruptions, local edema, or asthma were observed. No hemolysis was observed as evidenced by stable haptoglobin and LDH plasma levels.

Good hemocompatibility of the AA adsorber is extremely important as ECAT should be completed as quickly as possible after targeting the tumor to avoid unnecessary radiation exposure of vital organs. Coagulation was prevented with a bolus dose of heparin to the patient and continuous infusion of ACD-A to the extracorporeal circuit. This was sufficient to overcome the thrombogeneicity of the extracorporeal system, preventing thrombotic episodes and bleeding in the patients. Thrombotic episodes in particular, could occur as the blood flow through the extracorporeal system was relatively low and the patients' hematocrit relatively high. No thrombus or visible residual blood was seen in the AA adsorber or tubing set after termination of the ECAT. The decrease in B-thrombocytes can be mostly explained by hemodilution, but may also be due to adhesion, aggregation or loss in the extracorporeal circuit, as well as the patient's underlying disease and previous treatment. Different results have been obtained in studies of the effect of dialysis membranes on thrombocytes, and decreased, as well as unchanged, thrombocyte counts have been found with the use of the same kind of membrane (12). Transient leukopenia during hemodialysis due to sequestration mostly in the pulmonary circulation (13) has been considered to be caused by bloodmembrane interactions. This is most pronounced 15 minutes after the start of treatment. Complement activation is directly involved in this process. No leukopenia was observed in the present study, possibly due to the suppression of the immunological system and weak reaction to complement activation. Earlier ex vivo biocompatibility studies with AA adsorbent showed slight cell activation, with an increase in leukocyte elastase (7). 
Activation of the S-complement fragments $\mathrm{C} 3 \mathrm{a}$ and $\mathrm{C} 5 \mathrm{a}$ via the alternate pathway by different dialysis membranes has been used routinely as a measure of biocompatibility. Cellulose-based dialysis membranes show the highest degree of activation; newer synthetic noncellulose membranes cause much lower activation of the complement system. This activation, measured as serum levels of $\mathrm{C} 3 \mathrm{a}$ desArg, can lead to a three- to sevenfold increase, and is maximal 15 minutes after the start of dialysis, thereafter decreasing gradually, being restored to normal levels at the end of dialysis $(14,15)$. In comparison with the hemodialysis membranes currently in use, only weak activation of complement fragments, after passage of blood through AA adsorber, 30 minutes after start of ECAT, was observed in three patients and was probably not related to the treatment.

Activation of the kallikrein-kininogen pathways in contact with a polyacrylonitrile dialysis membrane may play a role in anaphylactic reactions in hemodialysis patients treated with converting enzyme inhibitors, which inhibits bradykinin degradation (16). In ex vivo studies (7) a significant (14-17 times) increase in P-bradykinin concentration was found 5 minutes after the start of blood perfusion via AA adsorbent. The level gradually declined to normal values during the following 40-80 minutes of the experiments. In our study, there was no increase in P-bradykinin concentration 15 minutes before, or after, passage through the AA adsorber.

We found no antiavidin antibodies, which would have been the case if leakage of avidin from the adsorber had occurred during ECAT. Avidin alone is not toxic, as was shown in the experiments involving injection of avidin molecules into the patients (17).

The very slight activation of complement fragments and lack of bradykinin activation could also be explained by the adsorption of $\mathrm{C} 3 \mathrm{a}, \mathrm{C} 5 \mathrm{a}$ and bradykinin to AA adsorbent. This mechanism has been suggested in hemodialysis membranes (18). At present, it is not possible to estimate the degree of adsorption of these blood components during ECAT, although there 
was no decrease $\mathrm{C} 3 \mathrm{a}$ and $\mathrm{C} 5 \mathrm{a}$ plasma concentration after the passage of blood through the AA absorber (Fig. 4). It should also be noted, that ECAT should not be directly compared to hemodialysis treatment as the dialysate may contain endotoxin molecules or bacterial DNA fragments which may contribute to cytokine induction leading to clinical consequences (19).

\section{Conclusion}

ECAT with an AA adsorber is an efficient, safe and highly biocompatible procedure, feasible for clinical use in patients with malignant diseases and probably also in most other clinical settings. The radionuclides used in the present system can possibly be replaced by toxins, enzymes or cytostatic drugs for improved tumor targeting with the same high biocompatibility. This high biocompatibility is expressed as high hemocompatibility with appriopriate anticoagulation and the lack of any effects on cellular elements of the blood, immunology status (complement fragments C3a, C5a), bradykinin and other blood tests. 


\section{Acknowledgments:}

This work was supported by grants from the Swedish Cancer Society; Mrs. Berta Kamprad's Foundation; the Gunnar, Arvid and Elisabeth Nilsson Foundation; the Gustaf V Jubilee Fund; the Medical Faculty of Lund University; Foundations of the Lund Health District Organization; Siv-Inger \& Per-Erik Andersson's Foundation; and Ingabritt \& Arne Lundbergs Foundation.

We would like to express our gratitude to Professor Scott Wilbur, University of Washington, Seattle, USA, for having developed the MitraTag. We would also like to thank Professor Anders Sjöholm and Eva Holmström for analysing the complement fragments and bradykinin. The technical assistance of Karin Fritz, Britt-Marie Petersson, Rigmor Nilsson, Karin Wingårdh, Dr. Lennart Darte and Dr. Tomas Ohlsson, is gratefully acknowledged. 


\section{References}

1. DeNardo GL, Maddock SW, Sgouros G, Scheibe PO, DeNardo SJ. Immunoadsorption: an enhancement strategy for radioimmunotherapy. J Nucl Med 1993;34:1020-1027.

2. Lindén O, Kurkus J, Garkavij M, Cavallin-Ståhl E, Ljungberg M, Nilsson R, Ohlsson T, Sandberg B, Strand SE, Tennvall J. A novel platform for radioimmunotherapy: extracorporeal depletion of biotinylated and (90)Y-labeled rituximab in patients with refractory B-cell lymphoma. Cancer Biother Radiopharm 2005;20:457-466.

3. Garkavij M, Tennvall J, Strand SE, Sjogren HO, JianQuing C, Nilsson R, Isaksson M. Extracorporeal whole-blood immunoadsorption enhances radioimmunotargeting of iodine125-labeled BR96-biotin monoclonal antibody J Nucl Med 1997;38:895-901.

4. Hakim RM. Clinical implications of hemodialysis membrane biocompatibility. Kidney Int $1993 ; 44: 484-494$.

5. Gurland HJ, Davison AM, Bonomini V, Falkenhagen D, Hansen S, Kishimoto T, Lysaght MJ, Moran J, Valek A. Definition and terminology in biocompatibility. Nephrol Dial Transplant 1994;9 (Suppl 2): 4-10.

6. Daugirdas JT, Ing TS. First use reactions during hemodialysis. A definition of subtypes. Kidney Int 1988;33(suppl 24) S-37-43.

7. Bosch T, Lennertz A, Duhr C, Fink E, Samtleben W. Ex vivo biocompatibility of avidinagarose: a new device for direct adsorption of biotinylated antibodies from human whole blood. Artificial Organs 2000;24:696-704.

8. Wang Z, Mårtensson L, Nilsson R, Bendahl PO, Lindgren L, Ohlsson T, Sjögren HO, Strand SE, Tennvall J. Blood pharmacokinetics of various monoclonal antibodies labeled with a new trifunctional chelating reagent for simultaneous conjugation with $1,4,7,10$ tetraazacyclododecane-N,N',N",N"'-tetraacetic acid and biotin before radiolabeling. Clin Cancer Res 2005;11:7171-7177. 
9. Wilbur DS, Chyan MK, Hamlin DK, Kegley BB, Nilsson R, Sandberg BE, Brechbiel M.

Trifunctional conjugation reagents. Reagents that contain a biotin and a radiometal chelation moiety for application to extracorporeal affinity adsorption of radiolabeled antibodies.

Bioconjug Chem 2002;13:1079-1092.

10. Nadler SB, Hidalgo JU, Bloch T. Prediction of blood volume in normal human adults. Sugery 1962;51:224-232.

11. Kahn R, Herwald H, Muller-Esterl W, Schmitt R, Sjögren AC, Truedsson L, Karpman D. Contact-system activation in children with vasculitis. Lancet 2002; 360 (9332): 535-541.

12. Ward RA. Effects of haemodialysis on coagulation and platelets: are we measuring membrane biocompatibility? Nephrol Dial Transplant 1995;10(Suppl 10): 12-17.

13. Hakin RM, Breillatt J, Lazarus JM, Port FK. Complement activation and hypersensitivity reactions to dialysis membranes. N Engl J Med 1984;311:878-882.

14. Dameche L, Brunet P, George F, André- Pinon S, Bernard D, Sampol J, Berland Y. Meltspun cellulose diacetate and polysulfone membranes have the same effect on complement activation and expression of leukocyte adhesion molecules and complement receptors. Nephrol Dial Transplant 1995;10(Suppl 10): 33-38.

15. Schaefer RM, Hörl WH, Kokot K, Heidland A. Enhanced biocompatibility with a new cellulosic membrane: cuprophan versus Hemophan. Blood Purif 1987;5:262-267.

16. Schulman G, Hakim R, Arias R, Silverberg M, Kaplan AP, Arbeit L. Bradykinin generation by dialysis membranes: possible role in anaphylactic reaction. JASN 1993;3:15631569.

17. Samuel A, Paganelli G, Chiesa R, Sudati F, Calvitto M, Melissano G, Grossi A, Fazio F. Detection of prosthetic vascular graft infection using avidin/indium-111-biotin scintigraphy. J Nucl Med 1996;37:55-61. 
18. CheungAK, Chenoweth DE, Otsuka D, Henderson LW. Compartmental distribution of complement activation products in artificial kidneys. Kidney Int 1986;30:74-80.

19. Schindler R, Beck W, Deppisch R, Aussieker M, Wilde A, Gohl H, Frei U. Short bacterial DNA fragments: detection in dialysate and induction of cytokines. JASN 2004;15:3207-3214. 


\section{Figure legends}

Fig. 1. The setup for ECAT. ACD, acid citrate dextrose; ACD-A, ACD solution, formula A. Fig. 2. The levels of B-leukocytes in seven patients at different times during ECAT. Normal values are between the two horizontal lines $\left(4.0-10.0 \times 10^{9} / \mathrm{L}\right)$. "Inlet" and "Outlet" denote samples analyzed immediately before and after passage through the AA adsorber, respectively.

Fig. 3. The levels of B-thrombocytes in seven patients at different times during ECAT. Normal values are between the two horizontal lines (140-400x10 $/ \mathrm{L})$. "Inlet" and "Outlet" denote samples analyzed immediately before and after passage through the AA adsorber, respectively.

Fig. 4. C3a and C5a plasma levels in seven patients at different times during ECAT. Median values are presented for each occasion. Normal values are between the two horizontal lines (C3a, 258-690 ng/mL, C5a, 1.3-7.8 ng/mL). "Inlet" and "Outlet" denote samples analyzed immediately before and after passage through the AA adsorber, respectively.

Fig. 5. Bradykinin plasma levels in seven patients at different times during ECAT. Mean values are presented for each occasion. The horizontal line shows the upper limit for normal values (1-174 ng/mL). "Inlet" and "Outlet” denote samples analyzed immediately before and after passage through the AA adsorber, respectively. 
Table 1. The clinical characteristics of the seven patients (five men, two women) and the ECAT protocol.

\begin{tabular}{|l|c|c|}
\hline & Mean $( \pm \mathrm{SD})$ & Range \\
\hline Body weight, kg & $70.1(12.8)$ & $55-89$ \\
\hline $\begin{array}{l}\text { Estimated blood } \\
\text { volume, } \mathrm{L}\end{array}$ & $4.7(0.84)$ & $3.54-5.72$ \\
\hline $\begin{array}{l}\text { Processed blood } \\
\text { volume, } \mathrm{L}\end{array}$ & $14.1(2.5)$ & $10.6-17.2$ \\
\hline Dose of heparin, IE & $8571(1336)$ & $7500-10000$ \\
\hline $\begin{array}{l}\text { Total dose of } \\
\text { ACD-A, } \mathrm{mL}\end{array}$ & $760(147)$ & $550-906$ \\
\hline $\begin{array}{l}\text { Volume of infused } \\
\text { NaCl, } \mathrm{mL}\end{array}$ & $214(8)$ & $200-300$ \\
\hline
\end{tabular}


Table 2. Clinical observations (vital signs) and parameters describing the performance of the AA adsorber in seven patients during ECAT.

\begin{tabular}{|l|c|c|c|c|}
\hline & \multicolumn{2}{|c|}{ Before ECAT } & \multicolumn{2}{c|}{ After ECAT } \\
\hline & Mean ( \pm SD) & Range & Mean ( \pm SD) & Range \\
\hline $\begin{array}{l}\text { Heart rate, beats per } \\
\text { min }\end{array}$ & $86(10)$ & $71-98$ & $83(14)$ & $68-107$ \\
\hline $\begin{array}{l}\text { Systolic blood } \\
\text { pressure, mmHg }\end{array}$ & $129(12)$ & $117-148$ & $131(14)$ & $108-144$ \\
\hline $\begin{array}{l}\text { Diastolic blood } \\
\text { pressure, mmHg }\end{array}$ & $78(8)$ & $68-89$ & $82(11)$ & $63-95$ \\
\hline $\begin{array}{l}\text { Body temperature, }{ }^{\circ} \mathrm{C} \\
\mathrm{n}=6\end{array}$ & $75(12)$ & $58-89$ & $79(13)$ & $63-93$ \\
\hline $\begin{array}{l}\text { Effective blood flow } \\
\text { rate, } \mathrm{mL} / \text { min }\end{array}$ & $127(48)$ & $30-150$ & $128(67)$ & $30-180$ \\
\hline $\begin{array}{l}\text { Adsorber pressure, } \\
\text { mmHg }\end{array}$ & $\mathrm{n}=6$ & $36.2-37.5$ & $36.8(0.5)$ & $36.4-37.7$ \\
\hline
\end{tabular}


Table 3. Results of blood tests in seven patients before and after ECAT.

\begin{tabular}{|c|c|c|c|c|c|c|}
\hline & & \multicolumn{2}{|c|}{ Before ECAT } & \multicolumn{2}{|c|}{ After ECAT } & \multirow{2}{*}{\begin{tabular}{|r}
$\mathrm{t}$-test paired \\
$\mathrm{p}$-value
\end{tabular}} \\
\hline Blood components & Normal range & Mean $( \pm$ SD $)$ & Range & Mean $( \pm$ SD $)$ & Range & \\
\hline Hemoglobin, g/L & $115-166$ & $121(5)$ & $113-126$ & $111(4.20)$ & $105-119$ & $<0.0001$ \\
\hline Haptoglobin, g/L & $0.24-1.90$ & $1.8(1)$ & $0.5-3.7$ & $1.5(0.9)$ & $0.4-3.3$ & 0.0107 \\
\hline $\mathrm{LDH}, \mu \mathrm{kat} / \mathrm{L}$ & $<8.0$ & $7.4(3.2)$ & $4.4-14$ & $6.9(3.1)$ & $3.8-13$ & 0.0147 \\
\hline Reticulocytes, $10^{9} / \mathrm{L}$ & $30-110$ & $51(17)$ & $31-77$ & $45(13)$ & $29-68$ & 0.0470 \\
\hline \begin{tabular}{|l} 
Leukocytes, $10^{9} / \mathrm{L}$ \\
\end{tabular} & $4.0-10.0$ & $5.4(1.7)$ & $3.3-8.2$ & $\begin{array}{c}6.4(0.8) \\
n=6\end{array}$ & $4.9-9$ & 0.0699 \\
\hline Thrombocytes, $10^{9} / \mathrm{L}$ & $140-400$ & $142(33)$ & $107-204$ & $123(29)$ & $86-172$ & 0.0239 \\
\hline Albumin, g/L & $36-45$ & $35(3)$ & $31-38$ & $30(3)$ & $26-34$ & $<0.0001$ \\
\hline $\begin{array}{l}\text { Ionized calcium, } \\
\mathrm{mmol} / \mathrm{L}(\mathrm{n}=6)\end{array}$ & $1.15-1.35$ & $1.21(0.03)$ & $1.17-1.27$ & $1.13(0.07)$ & $1.05-1.22$ & 0.0193 \\
\hline Total protein, $\mathrm{g} / \mathrm{L}$ & $43.6-71.1$ & $47.7(3.6)$ & $42.4-53.1$ & $42.6(2.6)$ & $38.4-45.1$ & 0.0002 \\
\hline
\end{tabular}




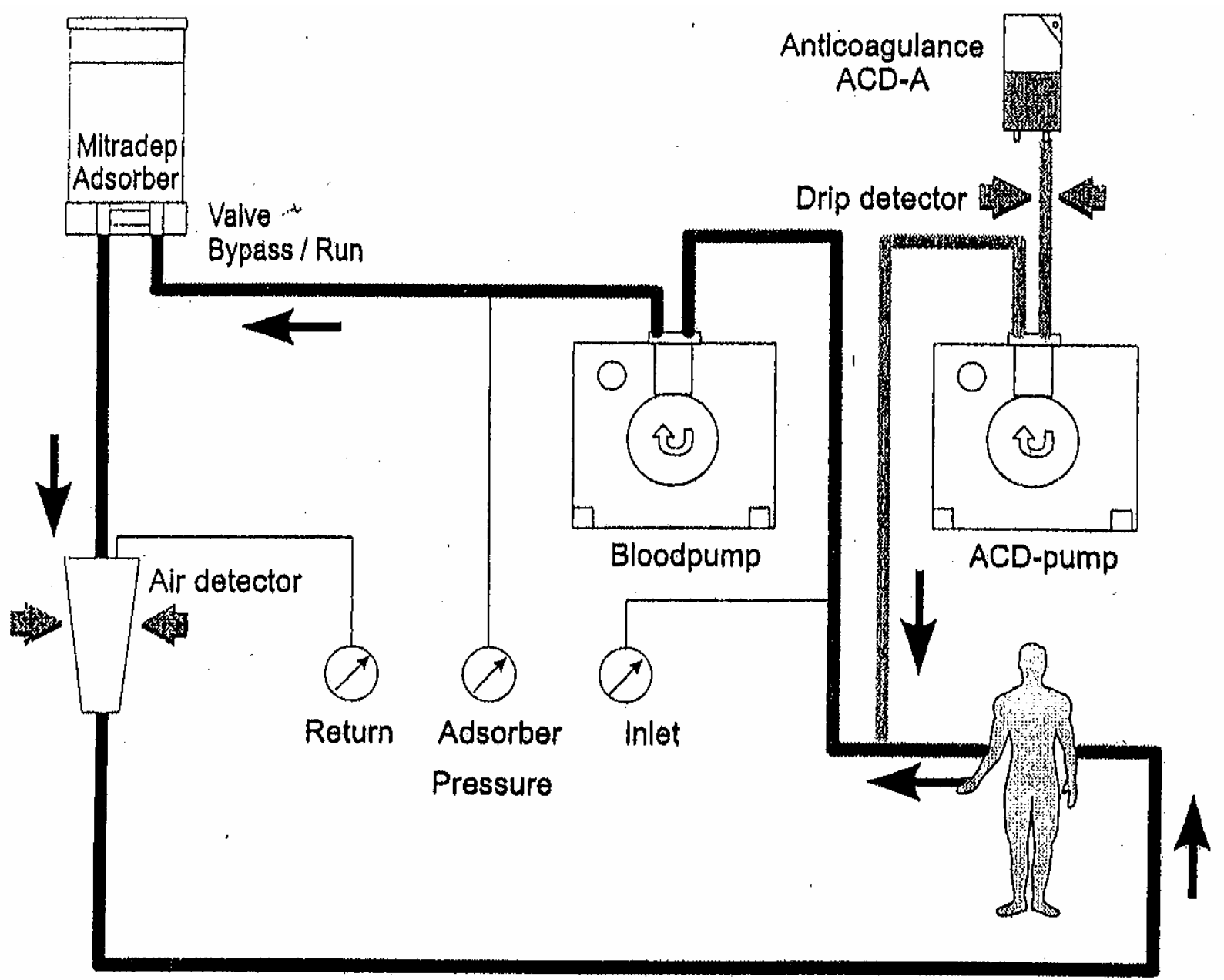

Fig. 1 


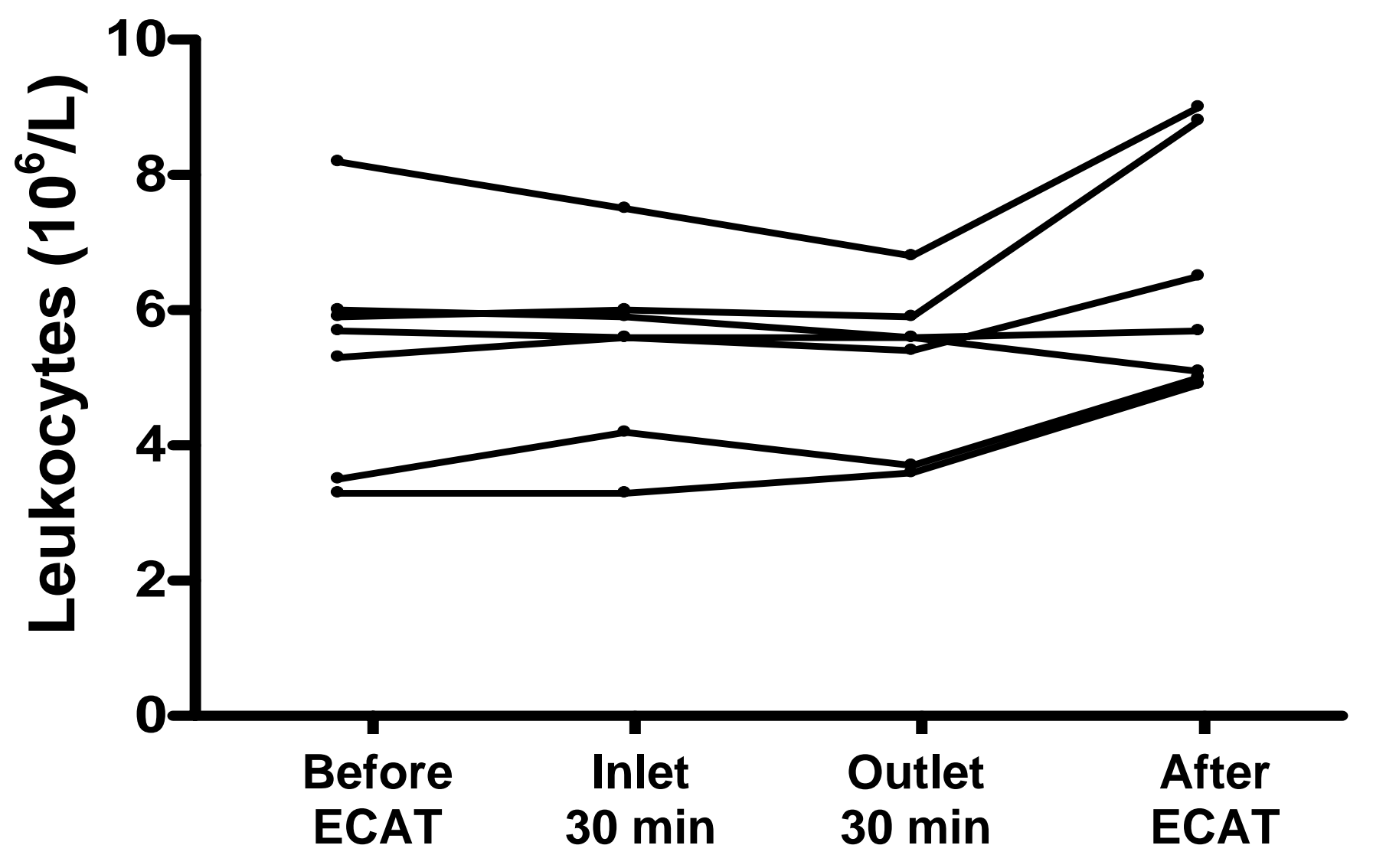

Fig. 2 


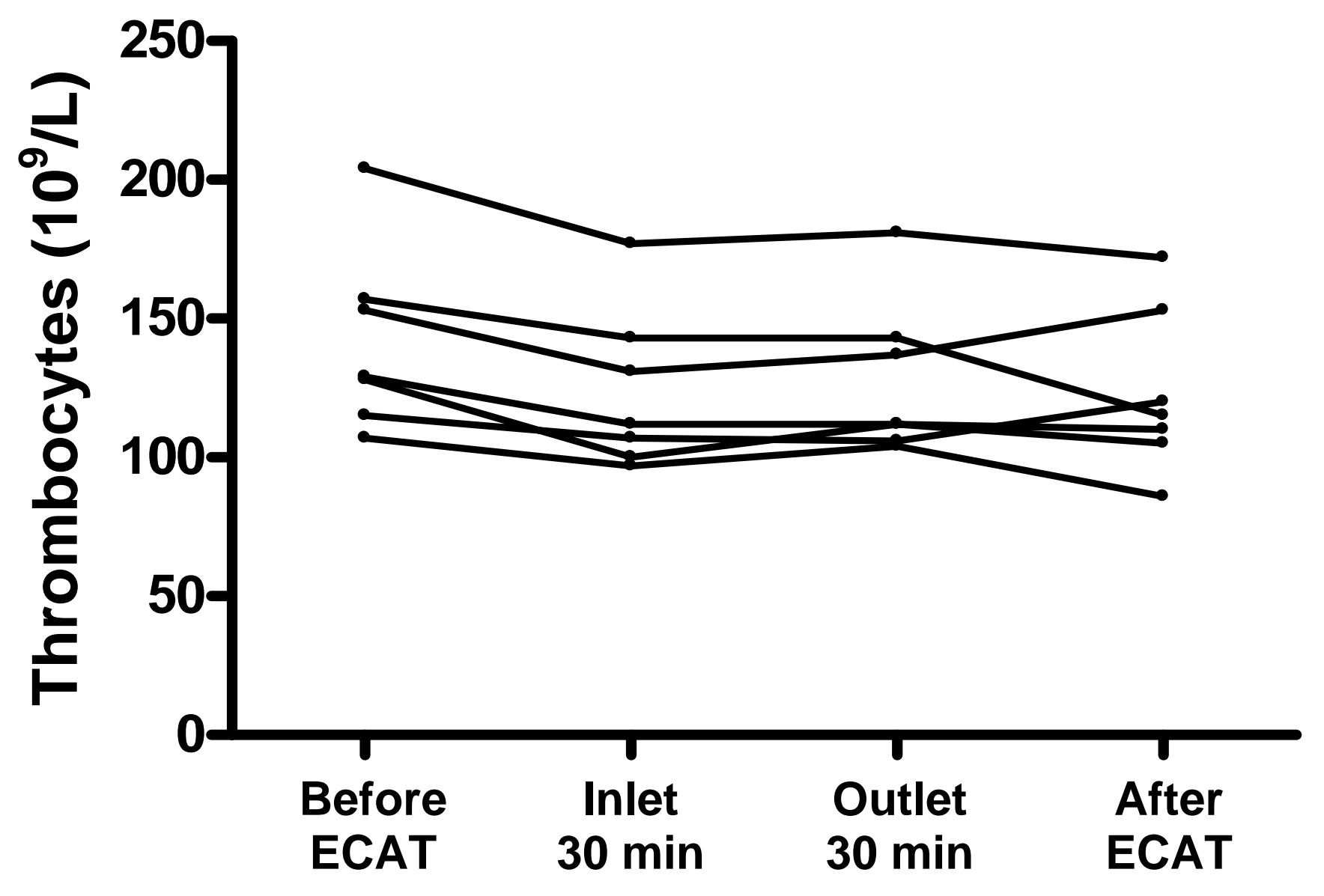

Fig. 3 


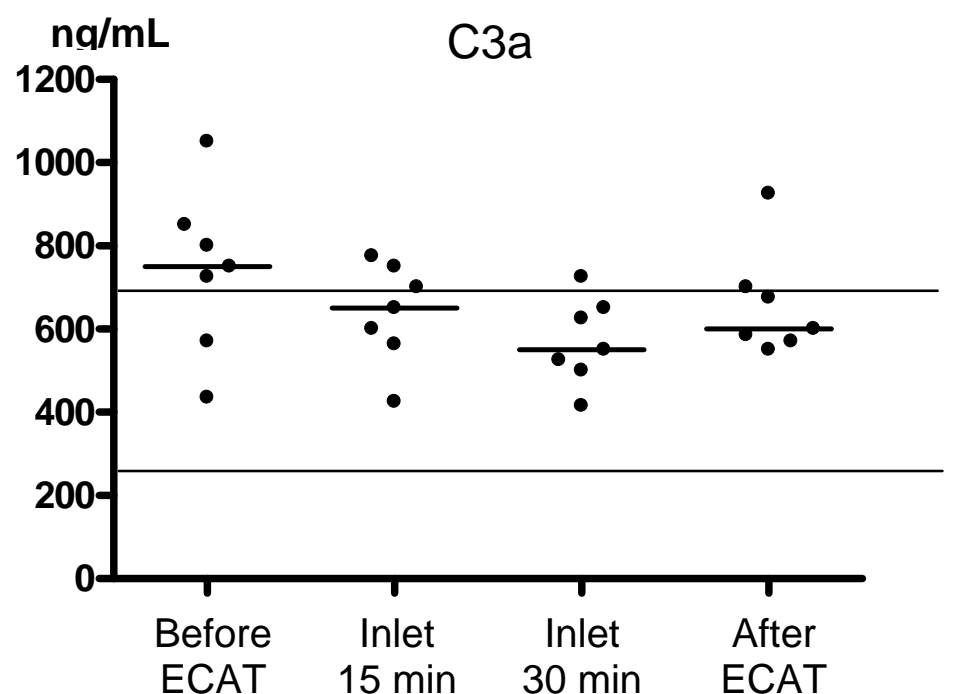

$\mathrm{nq} / \mathrm{mL}$
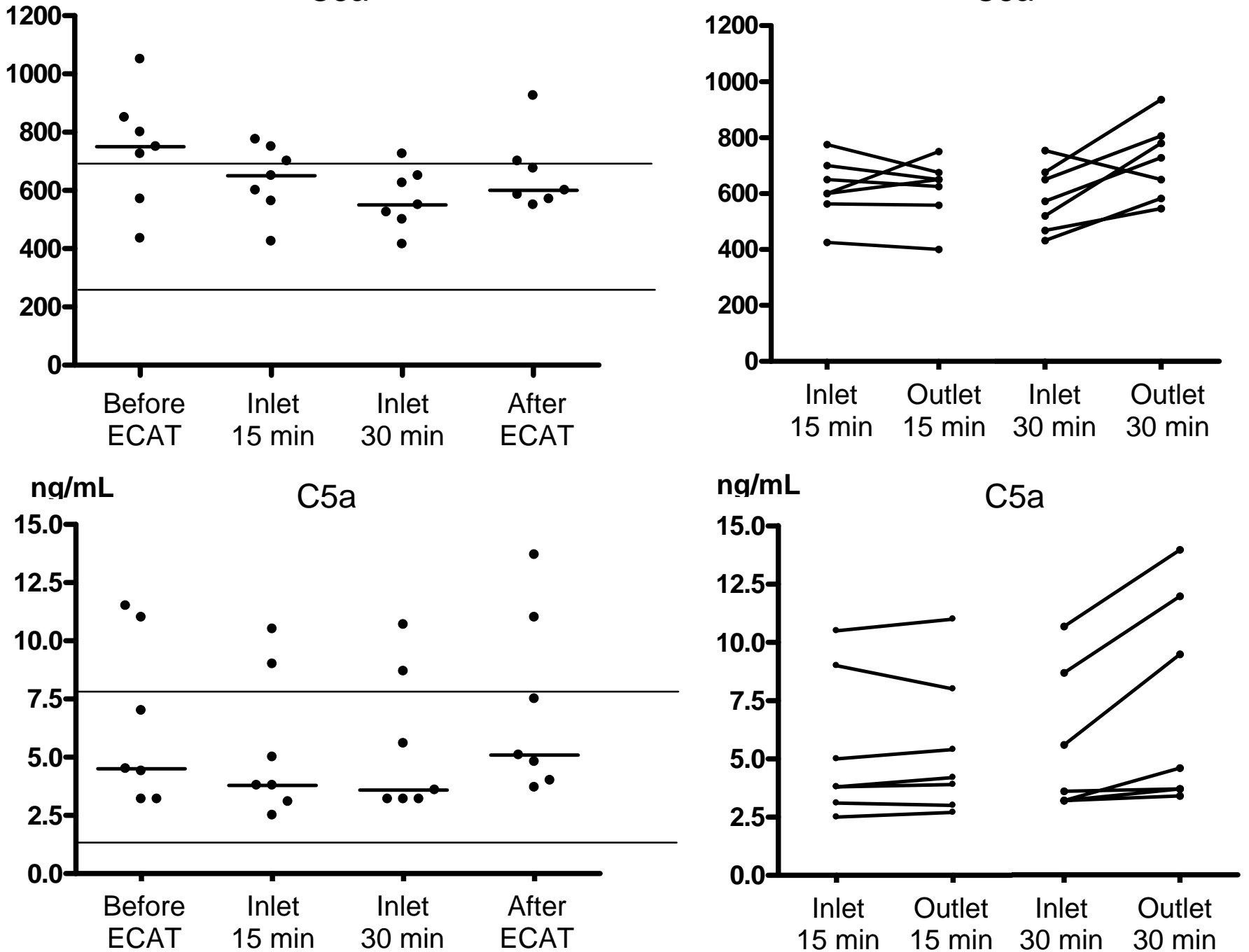


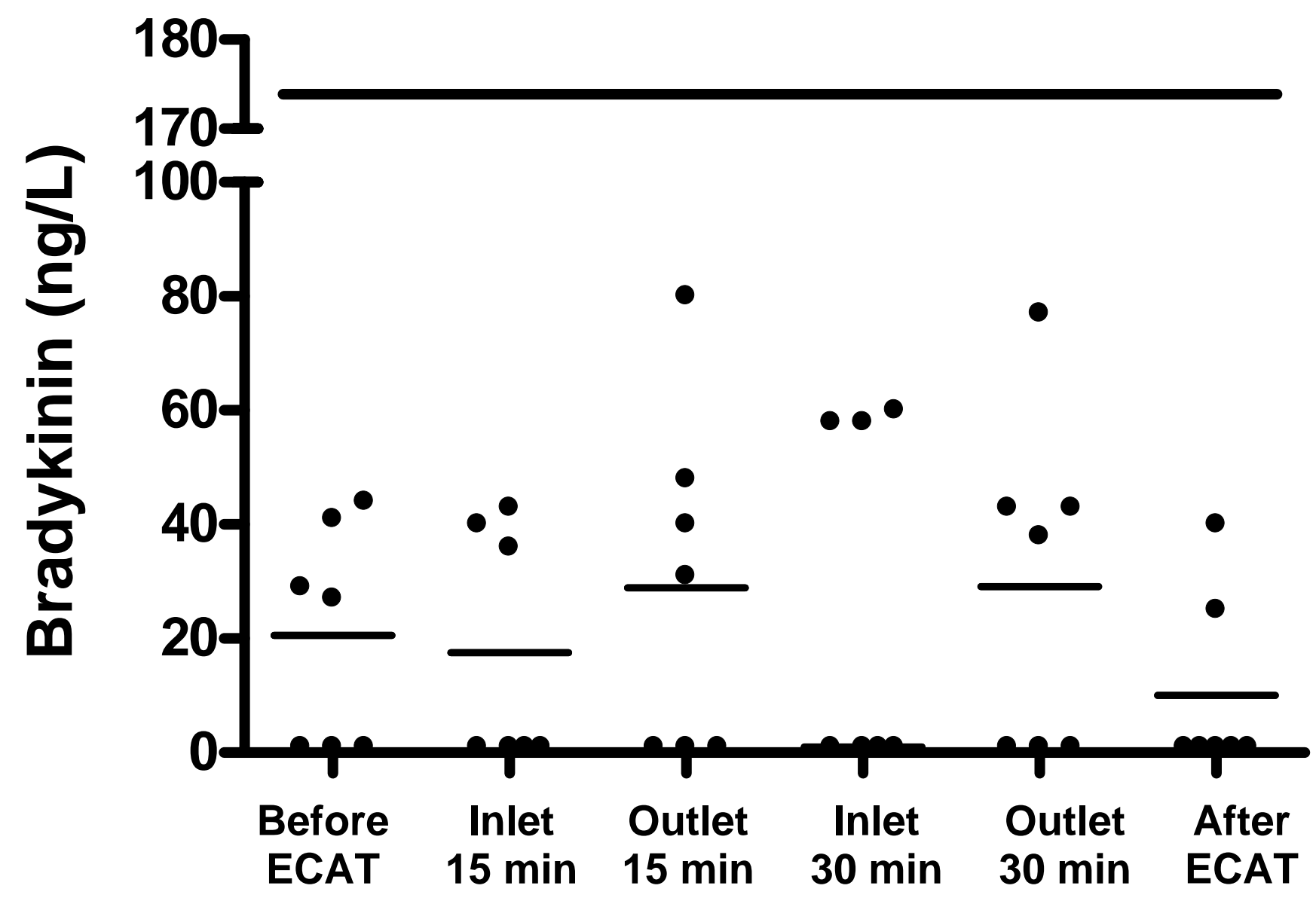

Fig. 5 